\title{
In Vitro Induction of the Acrosome Reaction in Frozen Thawed Spermatozoa from Different Cattle Breeds
}

\author{
Sabina VALEANU (NECULAI-VALEANU)*, Dan DRUGOCIU, Petru ROSCA \\ Department of Clinics, Faculty of Veterinary Medicine, University of Agronomical Sciences and \\ Veterinary Medicine, 8 Mihail Sadoveanu Alley, 700489 Iași, Romania \\ *Corresponding author email: sabina.valeanu@gmail.com \\ Bulletin UASVM Animal Science and Biotechnologies 72(1) / 2015 \\ Print ISSN 1843-5262; Electronic ISSN 1843-536X \\ DOI:10.15835/buasvmcn-asb:10493
}

\begin{abstract}
The standard acrosome reaction (AR) in cryopreserved semen doses of dairy and beef cattle breed was analyzed in this study. 18 frozen semen doses from 6 bulls ( 3 semen samples per bull) of 3 different cattle breeds (2 Charolais, 2 Holstein, 2 Fleckvieh) were in vitro incubated in three different test media (Heparin, BSA, or a Heparin-BSA system), using TALP medium, to induce in vitro acrosome reaction (AR). The percentage of acrosome reacted spermatozoa was evaluated using the Spermac dichromatic stain, at four different moment $(0,30,60$ or $120 \mathrm{~min}$.). At all time-points, the samples incubated with Heparin-BSA system showed a significant $(\mathrm{P}<0.05)$ higher percentage of acrosome-reacted spermatozoa as compared to the samples supplemented with Heparin or BSA alone, while the control media (without supplementation) showed the lowest results. A significant influence $(\mathrm{P}<0.05)$ of cattle breed on the dynamics of the in vitro induced AR was also observed. In our study, the response pattern of in vitro induced AR depended on the culture media, incubation time and nonetheless cattle breed. In consequence, these factors must be taken into consideration when assessing the sperm acrosome reaction in bulls.
\end{abstract}

Keywords: acrosome reaction, bull spermatozoa, Spermac stain

\section{INTRODUCTION}

In order to assess the fertilizing capacity of semen samples, the routine analysis of classical semen parameters might not be enough. Previous studies have suggested the use of in vitro acrosome reaction (AR) test might be a useful tool in predicting both field fertility and in vitro fertilizing capacity of bull semen (Lessard et al., 2011; Oettle, 1986).

\section{AIMS AND OBJECTIVES}

The aim of this study was to evaluate the induced acrosome reaction (AR) in cryopreserved semen doses of dairy and beef cattle breeds, taken into consideration the effect of breed, culture medium supplementation and incubation time on AR test results.

\section{MATERIALS AND METHODS}

18 frozen-thawed semen doses from 6 bulls (3 semen samples per bull) of 3 different cattle breeds (2 Charolais, 2 Holstein, 2 Fleckvieh) were used in this study. Aliquotes of $400 \mu \mathrm{L}$ of semen samples were isolated by swim-up preparation and incubated in vitro in three different test media (Heparin, BSA, or a Heparin-BSA system). To achieve capacitation, samples were incubated for 3 hours in TALP medium, at $39^{\circ} \mathrm{C}$ and $5 \% \mathrm{CO}_{2}$. The acrosome reaction was induced by adding 5mM calcium ionophore A23 187 (Sigma, Europe MO) and incubating the samples for $0,30,60$ or $120 \mathrm{~min}$ as described by Demyda-Peyras et al. (2012). The control samples did not contain ionophore. Spermac Stain was used according to the manufacture protocol to assess the acrosome 
Tab. 1. The percentage of frozen-thaw bull sperm from dairy and beef bulls that presented an acrosome reaction in Response to Calcium Ionophore Influx as assessed by Spermac Stain

\begin{tabular}{|c|c|c|c|c|c|c|c|c|c|c|c|c|c|c|c|c|}
\hline \multirow{2}{*}{$\begin{array}{c}\text { Bull } \\
\text { breeds }\end{array}$} & \multicolumn{4}{|c|}{$0 \mathrm{~min}$} & \multicolumn{4}{|c|}{$30 \mathrm{~min}$} & \multicolumn{4}{|c|}{$60 \mathrm{~min}$} & \multicolumn{4}{|c|}{120} \\
\hline & $\mathrm{C}$ & $\mathrm{H}$ & $\mathrm{B}$ & $\mathrm{H}+\mathrm{B}$ & $\mathrm{C}$ & $\mathrm{H}$ & $\mathrm{B}$ & $\mathrm{H}+\mathrm{B}$ & $\mathrm{C}$ & $\mathrm{H}$ & $\mathrm{B}$ & $\mathrm{H}+\mathrm{B}$ & $\mathrm{C}$ & $\mathrm{H}$ & $\mathrm{B}$ & $\mathrm{H}+\mathrm{B}$ \\
\hline Charolais & 34 & 42 & 42 & 49 & 39 & 51 & 50 & 55 & 42 & 56 & 57 & 63 & 45 & 63 & 64 & 73 \\
\hline Holstein & 34 & 43 & 40 & 50 & 37 & 50 & 50 & 56 & 43 & 57 & 56 & 65 & 44 & 63 & 64 & 77 \\
\hline Fleckvieh & 32 & 46 & 44 & 52 & 39 & 52 & 50 & 56 & 43 & 57 & 58 & 65 & 45 & 65 & 66 & 78 \\
\hline
\end{tabular}

Note: min=minutes; $\mathrm{C}=$ control; $\mathrm{H}=$ heparin; $\mathrm{B}=\mathrm{BSA} ; \mathrm{H}+\mathrm{B}=$ heparin+BSA system

reaction. Each sample was examined after staining, under oil immersion and 1000× magnification using a bright field microscope. From each smear, a total of 100 spermatozoa were evaluated for acrosome integrity. The sperm cells were assessed as having normal or altered acrosomes (Paulenz et al., 1995). The normal (acrosomal intact) sperm presented green acrosomal and pink postacrosomal regions, a thick green band with semi-circle form being observed at the tip of the sperm head. The acrosome-reacted/abnormal acrosome presented a pink acrosomal region, or green but the semi-circle band was either discontinuous or missing.

\section{RESULTS AND DISCUSSION}

At all time-points, the samples incubated with Heparin-BSA system showed a significant $(\mathrm{P}<0.05)$ higher percentage of acrosome-reacted spermatozoa as compared to the samples supplemented with Heparin or BSA alone, while the control media (without supplementation) showed the lowest results. A significant $(\mathrm{P}<0.05)$ influence of cattle breed on the dynamics of the in vitro induced AR was also observed (Tab. 1).

\section{CONCLUSION}

Acrosme reaction (AR) induction is a prospective technique in the prediction of both field fertility and IVF results for bull. The main advantages of this technique are the low costs and facility with which it can be executed, thus AR assay may be a useful tool in the increment of the animal improvement Birck et al. (2010).
The method could also be used as screening test, to identify sub-fertile or infertile bulls, as well as superior fertility bulls Lessard et al. (2011). In our study, the response pattern of in vitro induced AR depended on the culture media, incubation time and nonetheless cattle breed, our results being accordance with the discoveries made by DemydaPeyras et al. (2012). In consequence, these factors must be taken into consideration when assessing the sperm acrosome reaction in bulls.

Acknowledgements. This work was cofinanced from the European Social Fund through Sectoral Operational Programme Human Resources Development 2007-2013, project POSDRU.

\section{REFERENCES}

1. Birck A, Christensen P, Labouriau R, Pedersen J, Borchersen S (2010). In vitro induction of the acrosome reaction in bull sperm and the relationship to field fertility. Theriogenology, 73(9), 1180-91

2. Demyda-Peyras S., Dorado J., Hidalgo M., De Luca L., Muñoz-Serrano A., Moreno-Millan M. (2012). In vitro induction of the acrosome reaction in spermatozoa from endangered Spanish bulls: Effect of breed, culture media and incubation time, Livestock Science, 149, (3), 275-281

3. Lessard C, Siqueira LG., D’Amours O, Sullivan R, Leclerc P, Palmer C (2011). Infertility in a beef bull due to a failure in the capacitation process. Theriogenology 76, 891-899.

4. Paulenz H, Grevle IS, Andersen Berg K, Thomassen R (1995). The use of a dichromatic stain method (Spermac Stain) for determining changes in the acrosomal integrity of boar semen during cryopreservation. Reprod. Dom. Anim. 30, 113-116.

5. Oettle EE (1986). Using a new acrosome stain to evaluate sperm morphology. Veterinary Medicine, 81: 263-266. 